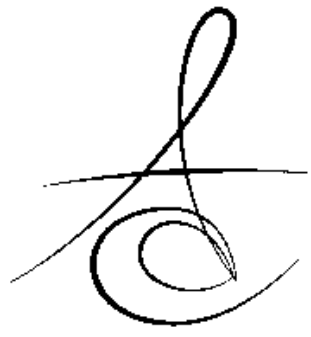

Makale Kodu/Article code: 2562

Makale Gönderilme tarihi: 21.01.2016

Kabul Tarihi: 03.03.2016

\section{REKÜRRENT AFTÖZ STOMATİT: GÜNCEL TEDAVİ YAKLAŞIMLARI}

\section{RECURRENT APHTHOUS STOMATITIS: RECENT THERAPEUTIC APPROACHES}

\author{
Yrd. Doç. Dr. Gökhan ÖZKAN*
}

Dt. Ali TOPTAŞ* öz

Rekürrent aftöz stomatit, yaygın, ağrılı, etiyolojisi kesin olarak bilinmeyen ve tekrar eden oral ülserlerden oluşur. Oral ülserler farklı sayı ve büyüklükte ortaya çıkabilir. Klinik olarak; minör, majör ve herpetiform olmak üzere üç alt grup altında toplanır. Bu ülserler, tek başına ortaya çıkabildiği gibi, bazı sistemik hastalıklarla beraber de görülebilir. Tedavisi genellikle semptomatiktir. Tedavisinde analjezikler, antiseptikler, antibiyotikler, kortikosteroidler ve lazer gibi ilaç ve yöntemler önerilir. Bu derlemede, rekürrent aftöz stomatitin olası etiyolojik faktörleri, klinik bulguları ve güncel tedavi alternatifleri tanımlanmaktadır.

Anahtar Kelimeler: Rekürrent aftöz stomatit, oral ülserler, tedavi

\section{GİRİŞ}

Rekürrent aftöz stomatit (RAS), oral mukozanın kronik, inflamatuvar ve ülseratif bir hastalığıdır ${ }^{1}$. RAS, toplumun \% 5-25'ini etkiler ve çoğunlukla 10-40 yaşlarında gözlenir. Oral mukozada en sık etkilenen bölgeler, ağız tabanı, sert ve yumuşak damak, yanak, vestibüler sulkus ve orofarinkstir ${ }^{2}, 3$. Tek veya daha fazla sayıda ortaya çıkan ağrılı, kendi kendini sınırlayan, sarı-beyaz renkte eritemli lezyonlardır ve hemen her zaman etrafı bir halka ile çevrilidir. Başlangıçta vezikül şeklinde başlar ve bu vezikülün çok kısa sürede patlamasıyla ülsere dönüşür. Kısa sürede vezikül formunun ortadan kalkması nedeniyle bu haline pek rastlanmaz ${ }^{3,4}$.

\section{Etiyoloji}

Etiyolojisi net olarak bilinmemekle birlikte, genetik faktörler, besin alerjisi, lokal travma, vitamin ve mineral eksiklikleri, endokrin değişiklikleri, stres,

\section{ABSTRACT}

Recurrent aphthous stomatitis compose of widespread, painful and recurring oral ulcers of unknown etiology. Oral ulcers may occur in different number and size. Clinically, it is divided into three subgroups as minor, major and herpetiformis. These ulcers can occur alone or can be seen with some systemic diseases. The treatment is usually symptomatic. Analgesics, antiseptics, antibiotics, corticosteroids and laser theraphy are recommended in the treatment. In this review, the possible etiological factors, clinical presentation and the current treatment alternatives of recurrent apthous stomatitis is described.

Key words: Recurrent aphthous stomatitis, oral ulcers, treatment

sigara bırakma, kimyasal maddeler ve mikrobiyal ajanlar predispozan olarak düşünülür. Ancak bu multifaktöriyel etiyopatogenez halen tam olarak anlaşılamamıştır ${ }^{5-9}$.

İnterlökinlerin (IL-1B, IL-2, IL-4, IL-5, IL-6, IL10, IL-12), interferon (IFN- $\gamma$ ) ve tümör nekroz faktörün (TNF-a) metabolizmasındaki değişikliklerle ortaya çıkması, hastalığın sık görüldüğü bireylerin çocuklarında da bu ülsere lezyonların oluşması ve ikizlerde yapılan çalışmalarda yatkınlık tespit edilmesi, çevresel etkenlerle birlikte genetik faktörlerin de etiyolojide etkili olduğunu göstermiştir ${ }^{10,11}$.

Çeşitli araştırmacılar, çikolata, gluten, inek sütü, fındık, gıda boyaları ve koruyucular gibi besin maddelerinin de RAS oluşumunda önemli rol oynadığı belirtilmişler, diğer bir grup araştırmacı da diyet alışkanlıklarının lezyon oluşumunda anlamlı bir etki yaratmadığını savunmuşlardır ${ }^{9,12}$.

\footnotetext{
*Adnan Menderes Üniversitesi, Diş Hekimliği Fakültesi, Ağız, Diş ve Çene Radyolojisi A.D.,
} 
Eguia-del Valle ve ark. ${ }^{13}$ aktif RAS lezyonu bulunan 20 hastada yaptıkları çalışmalarında 3 hastada tükürük kortizol seviyelerini yüksek bulurken kontrol hastalarında yüksek kortizol seviyesine rastlanmadığını belirtmişler; buna rağmen iki grup arasında istatistiksel bir fark bulunmadığını rapor etmişlerdir. Soto-Araya ve ark. ${ }^{14}$ ise RAS lezyonu gösteren hastalarda yaptıkları çalışmalarında \% 61 hastada stres, \% 83 hastada ise anksiyete görüldüğünü bildirmişlerdir. AlbanidouFarmaki ve ark. ${ }^{15}$ yaptıkları çalışmalarında anksiyete, tükürük ve serum kortizol seviyeleri ile RAS arasında pozitif korelasyon tespit etmişlerdir. Nadendla ve ark. ${ }^{16} \mathrm{da}$, inaktif faz RAS hastalarında anksiyete ve tükürük kortizol seviyelerinde benzer bir ilişki bulmuşlardır.

Helicobacter pylorihin de RAS oluşumunda etkili olduğu düşünülmektedir. Karaca ve ark. ${ }^{17}$ anti- $H$. pylori terapisinden sonra hastalarda RAS oluşumunun azaldığını bildirmişlerdir. Taş ve ark. ${ }^{18}$ da $H$. pylori pozitif hastalara uyguladıkları tedavinin ardından RAS lezyonlarıın azaldığını tespit etmişlerdir. Yine Yakar ve ark. ${ }^{19}$ da çalışmalarında kobalamin eksikliğine yol açan $H$. pylori gastritinin RAS oluşumunu tetikleyebileceğini savunmuşlardır.

Yapılan çalışmalar, bakteriyel ve viral enfeksiyonların etkisinin lezyon oluştuktan sonra ortaya çıktığını göstermiştir. RAS gözlenen hastalarda yapılan incelemelerde, demir, folik asit ve B12 vitamin eksiklikleri saptanmıştır. Yine de bu eksikliklerin giderilmesine rağmen her hastada iyileşme gözlenmemiş̧ir ${ }^{20,} 21$. Çinko eksikliğinin RAS'a yol açtığını gösteren yeni bir çalışma da rapor edilmiş̧tir ${ }^{22}$.

\section{Klinik}

RAS; klinik görünüm ve davranışına göre; minör (Mikulicz aftı), majör (Sutton aftı) ve herpetiform (Cook aftları) aftlar olmak üzere 3 alt grupta toplanır. Minör formu, aftların en sık görünen tipidir. Genellikle yuvarlak veya oval şekilli olup 10-14 günde skar bırakmadan kendiliğinden iyileşirler. Major formuna daha ender rastlanır. Genellikle tek bir ülser şeklinde oluşan büyük ve derin, minör afta göre daha ağrıı lezyonlardır. İyileşmeleri daha uzun sürer ve skarla sonuçlanabilir. Bazen ülserle beraber ateş de gözlenebilir. Orofarinkse ilerleyen lezyonlarda disfaji ve trismus da tabloya eşlik edebilir. Herpetiform aftlar ise daha küçük boyutlarda ve çok sayıda ülserler şeklinde ortaya çıkarlar. Minör formu gibi lezyonların iki hafta içinde iyileşmesi beklenir. Şekli nedeniyle Herpes lezyonlarından ayırt edilmesi gerekir ${ }^{4,6,20,23}$.

RAS, tek başına ortaya çıkabildiği gibi çeşitli sistemik hastalıkların bir parçası olarak da oluşabilir. Oral ve genital bölgede gözlenen aftlar, otoimmun ve inflamatuvar bir hastalık olan Behçet hastalığının başIıca bulgularındandır ${ }^{24,25}$. Çölyak ve Crohn hastalıkları, ülseratif kolit, siklik nötropeni ve AIDS gibi sistemik rahatsızlıklarda da sıklikla RAS gözlenir $6,9,23,26$.

RAS'ın oluşma sebeplerinin tam olarak belirlenememiş olması ve lezyonların geleneksel tedavilere her zaman yanit vermemesi nedeniyle; etiyolojik nedenler ve tedavi yöntemleri açısından yeni çalışmalara intiyaç duyulmaktadır. Detaylı bir anamnezin ardından uygun görülürse hastaya tam kan sayımı yaptırılarak, demir, folik asit ve B 12 vitamin eksikliklerinin tespit edilmesiyle, altta yatan problem ya da sistemik bir durumla ilişki belirlenebilir ${ }^{12,}{ }^{21}$.

\section{Tedavi}

Tedavisi lokal ve sistemik olarak iki grupta toplanır. Lokal tedavide, antiseptikler, antienflamatuvarlar, analjezikler, antibiyotikler, topikal kortikosteroidler, hyaluronik asit, topikal anestezikler ve lazer; sistemik tedavide ise çoğunlukla kortikosteroidler, antibiyotikler, kolşisin, çinko sülfat, immunoterapi ve homeopatik maddeler kullanilır 20, 27, 28 .

Güncel araştırmalarda çeşitli tedavi yöntemlerinin etkileri üzerinde çalışmalar yapılmışır. Bu konuda çalışma yapan araştırmacıların ortak görüşleri hastanın medikal hikayesi ve semptomlarına bağı olarak topikal ajanlarla tedaviyi başlatmaktır ${ }^{12}$. Topikal uygulamalara cevap vermeyen olgularda sistemik yaklaşım tercih edilebilir. Çeşitli çalışmalarda B 12 ve C vitaminleri ile uygulanan tedavi yaklaşımlarının RAS tedavisinde etkili olduğu savunulsa da, diğer bir grup araştımacı vitamin takviyesinin bu tedaviye herhangi bir katkısı bulunmadığını belirtmişlerdir 2, 12, 29 .

Aft tedavisi için reçete edilen bir diğer ilaç grubu non-steroid anti-inflamatuarlardır (NSAì̇). Mojabi ve ark. ${ }^{30}$ aft için kullanılan bir ilaç karışımına ibuprufen ekleyerek bu iki grubu karşılaştırmışlar, fakat anlamlı bir fark bulamamışlardır. Deshmukh ve ark. ${ }^{31}$ da zerdeçalda bulunan kürkümin ile triamsinolon asetonoid içeren jeli karşılaştırarak, kürküminin antioksidan, anti-inflamatuar, analjezik ve bağışıklık düzenleyici etkileri ile NSAi̇̇ grubuna göre RAS tedavisinde daha etkin olabileceğini bildirmişlerdir. 
Sharda ve ark. ${ }^{32}$ tarafından yürütülen bir çalışmada ise levamizolün kendi başına ya da düşük doz kortikosteroidle kombine edildiğinde, RAS tedavisinde etkili bir yöntem olarak kullanılabileceğini savunmuşlardır. Yine Darshan ve ark. ${ }^{33}$ antiinflamatuar bir ajan olan \% 5'lik amleksanoks pat ile diğer antiseptik, analjezik ve anestezik etki gösteren ajanları karşılaştırdıklarında, amleksanoks patın RAS görülme sıklığını, semptomlarını azalttığını ve iyileşme süresini kısalttığını bildirmişlerdir.

Sistemik kortikosteroidler, immunsupresan ajanlar, kolşisin, dapson ve talidomid grubu ilaçlar da RAS tedavisinde etkili olarak kullanılabilmektedir 10, 26, 33. Ancak bu ilaçların yan etkilerinin daha fazla olması sebebiyle dikkatli kullanımı çok önemlidir. Pakfetrat ve ark. ${ }^{34}$ kolşisin ve prednizolonu karşılaştırdıkları çalışmalarında, her iki ilacın da RAS semptomlarını gidermede aynı derecede etkili olduklarını rapor etmişlerdir. Sharquie ve ark. ${ }^{35}$ da çinko fosfat ile dapsonu karşlaştırmışlar ve her iki grubunda tedavide etkili olduğunu belirtmişlerdir; yine de çinko sülfatın daha hızlı iyileşme sağladığını savunmuşlardır.

Son dönem diş hekimliğinin birçok alanında kullanılmaya başlanan lazer yöntemi aft tedavisi için kullanılan yöntemlerden biridir. Sattayut ve ark. ${ }^{36} \mathrm{CO}_{2}$ lazerle yaptıkları çalışmada, lazerin aft ağrısını azalttığını, ancak tedavi yönünden yeterli etki göstermediğini belirtmişlerdir. Albrekston ve ark. ${ }^{28}$ 'nın düşük düzeyli lazeri plasebo ile karşılaştırdıkları çalışmalarında, lazerin diğer gruba göre ağrı ve yeme-içme, diş fırçalama gibi durumlarda oluşan rahatsızlıkları daha belirgin bir biçimde azalttığını rapor etmişlerdir. Tezel ve ark. ${ }^{37} \mathrm{da}, \mathrm{Nd}$-YAG lazerin ağrıyı daha kısa sürede azaltması, iyileşmeyi hızlandırması ve yan etkilerinin minimal olması sebebiyle, RAS tedavisinde ilaç tedavisinin yerine tercih edilebileceğini vurgulamışlardır.

Sonuç olarak, RAS lezyonları ağız mukozasında oldukça yaygın görülen, sık sık tekrar eden, hastanın konforunu olumsuz yönde etkileyen ülsere oluşumlardır. Tam olarak açıklanamayan etiyopatolojisi ve belirgin bir tedavi prosedürünün bulunmaması nedeniyle hekimler arasında fikir ayrılıklarının ortaya çıkması kaçınılmazdır. Hastalığı ortaya çıkaran nedenin tespit edilmesi, başarılı bir tedavinin ilk aşamasıdır. Etiyoloji konusunda henüz bir netlik bulunamaması bu konuda yeni çalışmalara intiyaç duyulduğunun göstergesidir. Hastanın sosyal, medikal ve sistemik durumu göz önüne alınarak belirlenecek bir tedavi şeması, sürecin iyileştirilmesinde oldukça önemli bir rol oynayacaktır. Bütün yönleri tam olarak tanımlanamamış bu tarz lezyonlarda hekime düşen görev, yan etkisi en az olan yöntemlerle tedaviyi başlatmak ve sürecin gidişine göre ileri tedavilere karar vermek olacaktır.

\section{KAYNAKLAR}

1. Çağlayan F, Yılmaz AB. Rekürrent aftöz stomatitis. Atatürk Üniv. Diş Hek. Fak. Derg 2009; 19: 47-54.

2. Chavan M, Jain H, Diwan N, Khedkar S, Shete A, Durkar S. Recurrent aphthous stomatitis: a review. J Oral Pathol Med 2012; 41: 577-83.

3. Riera Matute G, Riera Alonso E. [Recurrent aphthous stomatitis in Rheumatology]. Reumatol Clin 2011; 7: 323-8.

4. Ozbayrak S. Ağız Hastalıkları Atlası. 1.bs. EsenyurtIstanbul; Doğan Ofset: 2003. s. 18-23.

5. Slebioda Z, Szponar E, Kowalska A. Recurrent aphthous stomatitis: genetic aspects of etiology. Postepy Dermatol Alergol 2013; 30: 96-102.

6. Slebioda Z, Szponar E, Kowalska A. Etiopathogenesis of recurrent aphthous stomatitis and the role of immunologic aspects: literature review. Arch Immunol Ther Exp (Warsz) 2014; 62: 205-15.

7. Gallo Cde B, Mimura MA, Sugaya NN. Psychological stress and recurrent aphthous stomatitis. Clinics (Sao Paulo) 2009; 64: 645-8.

8. Wardhana, Datau EA. Recurrent aphthous stomatitis caused by food allergy. Acta Med Indones 2010; 42: 236-40.

9. Preeti L, Magesh K, Rajkumar K, Karthik R. Recurrent aphthous stomatitis. J Oral Maxillofac Pathol 2011; 15: 252-6.

10. Eguia-del Valle A, Martinez-Conde-Llamosas $R$, Lopez-Vicente J, Uribarri-Etxebarria A, AguirreUrizar JM. Salivary levels of Tumour Necrosis Factor-alpha in patients with recurrent aphthous stomatitis. Med Oral Patol Oral Cir Bucal 2011; 16: e33-6.

11. Ozyurt K, Celik A, Sayarlioglu M, Colgecen E, Inci R, Karakas T, Kelles M, Cetin GY. Serum Th1, Th2 and Th17 cytokine profiles and alpha-enolase levels in recurrent aphthous stomatitis. J Oral Pathol Med 2014; 43: 691-5. 
12. Belenguer-Guallar I, Jimenez-Soriano $Y$, Claramunt-Lozano A. Treatment of recurrent aphthous stomatitis. A literature review. J Clin Exp Dent 2014; 6: e168-74.

13. Eguia-del Valle A, Martínez-Conde-Llamosas $R$, López-Vicente J, Uribarri-Etxebarria A, AguirreUrizar JM. Salivary cortisol determination in patients from the Basque Country with recurrent aphthous stomatitis. A pilot study. Med Oral Patol Oral Cir Bucal 2013; 18: e207.

14. Soto AM, Rojas AG, Esguep A. Association between psychological disorders and the presence of Oral lichen planus, Burning mouth syndrome and Recurrent aphthous stomatitis. Med Oral 2004; 9: 1-7.

15. Albanidou-Farmaki E, Poulopoulos AK, Epivatianos A, Farmakis K, Karamouzis M, Antoniades D. Increased anxiety level and high salivary and serum cortisol concentrations in patients with recurrent aphthous stomatitis. Tohoku J Exp Med 2008; 214: 291-6.

16. Nadendla LK, Meduri V, Paramkusam G, Pachava $\mathrm{KR}$. Relationship of salivary cortisol and anxiety in recurrent aphthous stomatitis. Indian J Endocrinol Metab 2015; 19: 56-9.

17. Karaca S, Seyhan M, Senol M, Harputluoglu MM, Ozcan A. The effect of gastric Helicobacter pylori eradication on recurrent aphthous stomatitis. Int J Dermatol 2008; 47: 615-7.

18. Arslan Taş D, Yakar T, Sakalli H, Serin E. Impact of Helicobacter pylori on the clinical course of recurrent aphthous stomatitis. J Oral Pathol Med 2013; 42: 89-94.

19. Yakar T, Serin E, Coşar AM, Arslan Taş D, Ataç FB. The relationship of recurrent aphthous stomatitis and Helicobacter pylori, cytokine gene polymorphism and cobalamin. Turk J Gastroenterol 2015; 26: 304-8.

20. Liang MW, Neoh CY. Oral aphthosis: management gaps and recent advances. Ann Acad Med Singapore 2012; 41: 463-70.

21. Kozlak ST, Walsh SJ, Lalla RV. Reduced dietary intake of vitamin B12 and folate in patients with recurrent aphthous stomatitis. J Oral Pathol Med 2010; 39: 420-3.

22. Ozler GS. Zinc deficiency in patients with recurrent aphthous stomatitis: a pilot study. J Laryngol Otol 2014; 128: 531-3.
23. Patil S, Reddy SN, Maheshwari S, Khandelwal S, Shruthi D, Doni B. Prevalence of recurrent aphthous ulceration in the Indian Population. J Clin Exp Dent 2014; 6: e36-40.

24. Rhee SH, Kim YB, Lee ES. Comparison of Behcet's disease and recurrent aphthous ulcer according to characteristics of gastrointestinal symptoms. J Korean Med Sci 2005; 20: 971-6.

25. Seoudi N, Bergmeier LA, Drobniewski F, Paster B, Fortune $F$. The oral mucosal and salivary microbial community of Behcet's syndrome and recurrent aphthous stomatitis. J Oral Microbiol 2015; 7: 27150.

26. Shakeri R, Zamani $F$, Sotoudehmanesh R, Amiri A, Mohamadnejad $M$, Davatchi $F$, Karakani AM, Malekzadeh R, Shahram F. Gluten sensitivity enteropathy in patients with recurrent aphthous stomatitis. BMC Gastroenterol 2009; 9: 44.

27. Scully C, Hodgson T. Recurrent oral ulceration: aphthous-like ulcers in periodic syndromes. Oral Surg Oral Med Oral Pathol Oral Radiol Endod 2008; 106: 845-52.

28. Albrektson M, Hedstrom L, Bergh H. Recurrent aphthous stomatitis and pain management with low-level laser therapy: a randomized controlled trial. Oral Surg Oral Med Oral Pathol Oral Radiol 2014; 117: 590-4.

29. Lalla RV, Choquette LE, Feinn RS, Zawistowski $H$, Latortue MC, Kelly ET, Baccaglini L. Multivitamin therapy for recurrent aphthous stomatitis: a randomized, double-masked, placebo-controlled trial. J Am Dent Assoc 2012; 143: 370-6.

30. Borhan-Mojabi K, Mirmiran F, Nassiri-Asl M, Nazeman $\mathrm{P}$, Jahanihashemi $\mathrm{H}$. Therapeutic Effects of "Ibuprofen, Diphenhydramine and Aluminium MgS" on Recurrent Aphthous Stomatitis: A Randomized Controlled Trial. J Dent (Tehran) 2014; 11: 167-71.

31. Deshmukh RA, Bagewadi AS. Comparison of effectiveness of curcumin with triamcinolone acetonide in the gel form in treatment of minor recurrent aphthous stomatitis: A randomized clinical trial. Int J Pharm Investig 2014; 4: 138-41.

32. Sharda N, Shashikanth MC, Kant $P$, Jain $M$. Levamisole and low-dose prednisolone in the treatment of reccurent aphthous stomatitis. J Oral Pathol Med 2014; 43: 309-16. 
33. Darshan $D D$, Kumar $C N$, Kumar $A D$, Manikantan NS, Balakrishnan D, Uthkal MP. Clinical study to know the efficacy of Amlexanox 5\% with other topical Antiseptic, Analgesic and Anesthetic agents in treating minor RAS. J Int Oral Health 2014; 6: 511.

34. Pakfetrat A, Mansourian A, Momen-Heravi F, Delavarian Z, Momen-Beitollahi J, Khalilzadeh $\mathrm{O}$, Basir-Shabestari S. Comparison of colchicine versus prednisolone in recurrent aphthous stomatitis: A double-blind randomized clinical trial. Clin Invest Med 2010; 33: E189-95.

35. Sharquie KE, Najim RA, Al-Hayani RK, Al-Nuaimy AA, Maroof DM. The therapeutic and prophylactic role of oral zinc sulfate in management of recurrent aphthous stomatitis (ras) in comparison with dapsone. Saudi Med J 2008; 29: 734-8.

36. Sattayut S, Trivibulwanich J, Pipithirunkarn N, Danvirutai $\mathrm{N}$. A clinical efficacy of using $\mathrm{CO} 2$ laser irradiating to transparent gel on aphthous stomatitis patients. Laser Ther 2013; 22: 283-9.

37. Tezel A, Kara C, Balkaya V, Orbak R. An evaluation of different treatments for recurrent aphthous stomatitis and patient perceptions: Nd:YAG laser versus medication. Photomed Laser Surg 2009; 27: 101-6.

\section{Yazışma Adresi}

Yrd. Doç. Dr. Gökhan ÖZKAN, Adnan Menderes Üniversitesi, Diş Hekimliği Fakültesi, Ağız, Diş ve Çene Radyolojisi A.D. 09010, Aydın-Türkiye Tel: 90-506-500 9470

E-mail: asgokhanozkanus@hotmail.com 